\title{
PH90
}

\section{Atalaya3D: el portal virtual de patrimonio de las universidades andaluzas}

\begin{abstract}
En el marco del Observatorio Atalaya, los Vicerrectorados de Extensión y Cultura de las universidades públicas andaluzas, conscientes del variado y rico patrimonio cultural que atesoran, impulsaron el proyecto de Portal Virtual de Patrimonio de las Universidades Andaluzas, coordinado por la Universidad de Granada, con el fin de conseguir la difusión del mismo y su puesta en valor y visibilización. Actualmente es una plataforma web mediante la que cualquier navegante puede acceder a información textual y gráfica de las principales obras del patrimonio de las diez universidades públicas de Andalucía.
\end{abstract}

M. ${ }^{a}$ Luisa Bellido Gant, Francisco Javier Melero Rus | Universidad de Granada

URL de la contribución <www.iaph.es/revistaph/index.php/revistaph/article/view/3809>

El principal objetivo del Portal Virtual de Patrimonio de las Universidades Andaluzas (http://patrimonio3d.ugr. es) es difundir el patrimonio de las universidades andaluzas de forma accesible y atractiva, tanto para el público general como para investigadores especializados. Para cada pieza incluida en el portal, el visitante accede a una ficha donde se muestra la información más relevante, tanto a nivel técnico (autor, cronología, dimensiones, material, etc.) como descriptivo y la bibliografía relacionada. Además, se ofrece al visitante una experiencia más natural de navegación y una cantidad de datos más abordable por el público general, incluyendo más recursos gráficos y la posibilidad de visualizar vídeos y modelos 3D en tiempo real, sin renunciar al rigor de la información mostrada.

Al pretender visualizar en 3D las piezas más representativas del patrimonio universitario, este proyecto alcanza otro objetivo, no menos importante que el de la difusión, la documentación precisa y exacta en tres dimensiones del patrimonio cultural de las universidades participantes. De esta forma, disponemos de modelos 3D obtenidos con una alta precisión, que sirven también como una documentación muy valiosa que puede ser utilizada por los equipos de restauración-conservación de las distintas Universidades. Para ello, el proyecto se apoya en los dispositivos de adquisición más avanzados del mercado y un equipo de investigadores y profesionales con gran experiencia al cargo de las labores técnicas (en concreto profesores del Grupo de investigación TIC-236 y profe- sionales del departamento. Backup3D de la spin-off de la Universidad de Granada AgeO). Los bienes muebles son digitalizados con una resolución de $0.3 \mathrm{~mm}$ (10 puntos por $\mathrm{mm}^{2}$ ) y un error medio de $0.03 \mathrm{~mm}$, utilizando para ello un escáner de luz blanca estructurada que se calibra antes de cada escaneo para obtener la mayor fidelidad con la pieza original. Las salas y edificios patrimoniales son digitalizados con un escáner láser que ofrece resoluciones de hasta $1 \mathrm{~mm}$, capturando tanto el color como la geometría del bien.

El Portal Virtual es un proyecto en continua evolución y ampliación. Hay más de 300 fichas en la base de datos, teniendo un $20 \%$ de ellas información tridimensional en forma de un modelo 3D que puede ser examinado por el visitante sin necesidad de instalar ningún software adicional, sino con su simple navegador.

Esta visualización 3D en la web hace del proyecto algo totalmente pionero a nivel nacional, pues permite al visitante observar las obras desde cualquier ángulo y distancia interactivamente. Hasta el año 2015 se ha utilizado X3D como tecnología estándar de visualización y composición de escenas 3D en la Web.

Actualmente se está en proceso de incluir el catálogo de modelos 3D en la plataforma Sketchfab ${ }^{\circledR}$ (www. sketchfab.com/atalaya3d) Esta plataforma se está convirtiendo en el principal medio de difusión de modelos $3 \mathrm{D}$ en la web, fácilmente integrables en redes sociales 


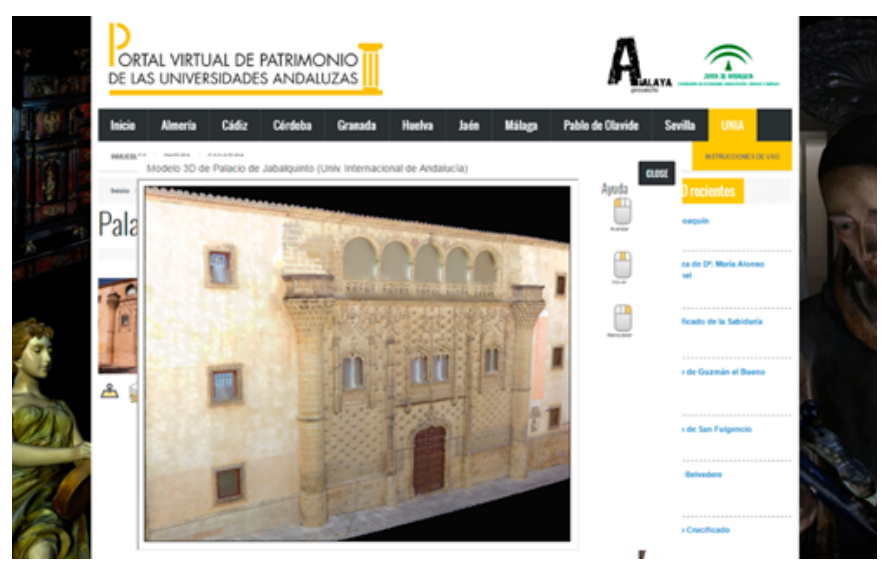

Modelo 3D de la fachada del palacio de Jabalquinto (UNIA)

como Facebook y Twitter, y en la cual el Portal Virtual se encuentra al mismo nivel que otras instituciones museísticas como el British Museum o el Museo Arqueológico Nacional de España.

Estos modelos 3D, desde los orígenes del portal, son accesibles no sólo desde un ordenador, sino que también son visibles mediante dispositivos móviles como los teléfonos inteligentes o las tablets. Por razones de usabilidad y accesibilidad, los modelos subidos a la web son versiones simplificadas del resultado de la digitalización. Los modelos 3D de alta precisión originales quedan a disposición de sus universidades propietarias.

Además, el disponer de los modelos 3D facilita crear infografías animadas que, gracias a las redes sociales, permiten una fácil difusión del patrimonio universitario. Hasta el momento se han creado 36 vídeos, muchos de los cuales ya están en YouTube y son accesibles por cualquier usuario a través de la visita al portal web y el resto están en proceso de edición.

Se trata pues de un proyecto en el que participan todas las universidades públicas andaluzas y que pretende acercar el patrimonio universitario a un público interesado como primer paso para su difusión, puesta en valor y conservación de los bienes que lo integra.

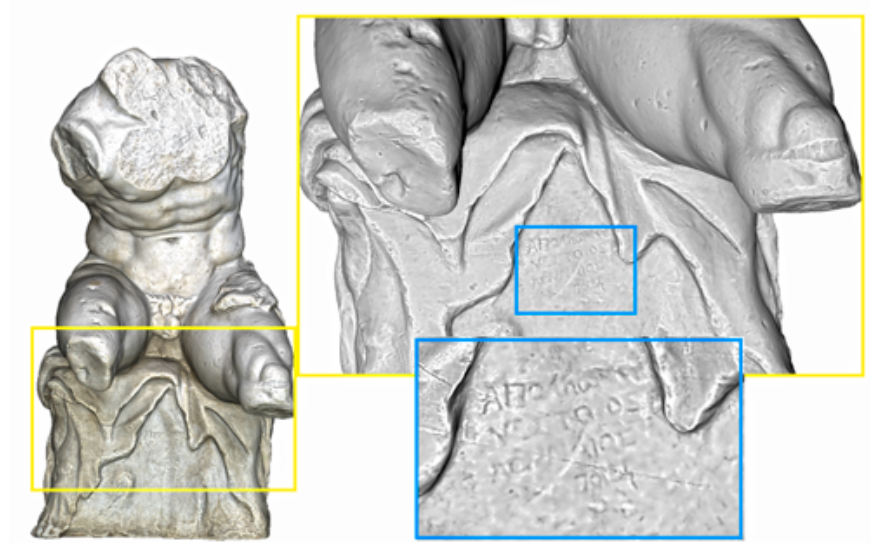

Torso de Belvedere del patrimonio de la Universidad de Sevilla

\section{BIBLIOGRAFÍA}

- JIMÉNEZ, J. G.; GARCÍA, M.; REVELLES, J.; MELERO, F. J. (2012) Digitalización 3D y Difusión en Web del Patrimonio de las Universidades Andaluzas mediante X3D Y WebGL. Virtual Archaeology Review, vol. 3, 2012, pp. 55-59

- MAGNOR, M.; GRAU, O.; SORKINE-HORNUNG, O. et ál. (ed.) (2015) Digital Representations of the Real World: How to Capture, Model, and Render Visual Reality. A K Peters/CRC Press, 2015

- MELERO, F. J.; JIMÉNEZ, J. G. (2012) Digitalización y Virtualización 3D en la Web de obras de arte. En El Patrimonio Cultural y Natural como Motor de Desarrollo, Investigación e Innovación. Sevilla: Universidad Internacional de Andalucía, 2012

- REVElLES, J.; MELERO, F. J. (2014) El Portal Virtual de Patrimonio de las Universidades Andaluzas. En XXIV Congreso Español de Informática Gráfica (CEIG 2014), Zaragoza, 2014.

- RODRíguez ORTEGA, N. (2016) Portal Virtual del Patrimonio de las Universidades Andaluzas se une a la \#MuseumWeek. En Dixit: plataforma editorial de ReArte.Dix $<$ http://historiadelartemalaga.uma.es/dixit/el-portal-virtualde-patrimonio-de-las-universidades-andaluzas-se-une-a-lamuseumweek/> [Consulta: 03/07/2016]

- VOZMEDIANO, E. (2016) Museos universitarios de arte en el mundo. El Cultural de El Mundo, Enero 2016 <http:// www.elcultural.com/blogs/y-tu-que-lo-veas/2016/01/museosuniversitarios-de-arte-en-el-mundo/> [Consulta: 08/07/2016] 